tions of circulating androgens and oestrogens and, when the patients are anovulatory, by a relative deficiency of progesterone. Progesterone has a stabilising effect on membranes. Perhaps reduced stability of membranes in the muscle of the urethral sphincter allows circuitous excitatory pathways between muscle fibres to be established. The suggestion that progesterone deficiency is important remains speculative, particularly because anovulatory menstrual cycles are fairly common and this bladder disturbance is unusual: the high levels of androgens in the polycystic ovary syndrome are probably not important as this type of activity has not been found in men, even young men with unexplained obstructed voiding.

Electromyography of the urethral sphincter and its interpretation require some skill; if this is not available ovarian ultrasonography may contribute useful information about the pathogenesis of otherwise unexplained urinary retention in women.

We thank Mr R T Turner-Warwick, Mr E J G Milroy, Mr P H L Worth, Mr J L Osborne, Mr W F Hendry, and Mr S J Steele for allowing us to study their patients, and Ms J Adams and her colleagues, whose skill in ultrasonography formed an essential part of the study.

1 Fowler CJ, Kirby RS. Abnormal electromyographic activity (decelerating burst and complex repetitive discharges) in the striated muscle of the urethral sphincter in 5 women with persisting urinary retention. $\mathrm{Br} f \mathrm{Urol}$ 1985;57:69-70

2 Fowler CJ, Kirby RS, Harrison MJG. Decelerating burst and complex repetitive discharges in the striated muscle of the urethral sphincter, associated with urinary retention in women. $\mathcal{F}$ Neurol Neurosurg Psychiatry $1985 ; 48: 1004-9$.

3 Fowler CJ, Kirby RS. Electromyography of urethral sphincter in women with urinary retention. Lancet 1986; ; 1455-6.

4 Allen TD. Psychogenic urinary retention. South Med f 1972;65:302-4

5 Adams J, Franks S, Polson DW, et al. Multifollicular ovaries: clinical and endocrine features and response to pulsatile gonadotrophin releasing hormone. Lancet 1985;ii:1375-8.

6 Franks S, Adams J, Mason H, Polson D. Ovulatory disorders in women with polycystic ovary syndrome. Clinics in Obstetrics and Gynaecology 1985;12 605-32.

7 Jacobs HS. Polycystic ovaries and polycystic ovary syndrome. Gynaecological Endocrinology 1987;1:113-31.

8 Adams J, Polson DW, Franks S. Prevalence of polycystic ovaries in women with anovulation and idiopathic hirsutism. Br Med f 1986;293:355-9.

9 Frankssen C, Petersen I. Investigation of disturbances in the striated muscle of the urethral sphincter. Br f Urol 1955;27:154-61.

10 Blaivas JG, Labib KL, Bauer SB, Retik AB. A new approach to electromyography of the external urethral sphincter. F Urol 1977;117:773-7.

11 Fowler CJ, Kirby RS, Harrison MJ, Milroy FJ, Turner-Warwick R. Individual motor unit analysis in the diagnosis of disorders of urethral sphincter innervation. F Neurol Neurosurg Psychiatry 1984;47:637-41.

12 Miller JA, Jacobs HS. Treatment of hirsutism and acne with cyproterone acetate. Clinics in Endocrinology and Metabolism 1986;15:373-89.

13 Butler WJ. Pseudomyotonia of the periurethral sphincter in women with urinary incontinence. $\mathcal{F}$ Urol 1979;122:838-40.

14 Potenzoni D, Juvarra G, Bettoni L, Stagha G. Pseudomyotonia of the striated urethral sphincter. F Urol 1983;130:512-3.

15 Dyro FM, Bauer SB, Hallett $M$, et al. Complex repetitive discharges in the external urethral sphincter in the pediatric population. Neurology and Urodynamics 1983;2:39-44.

16 Polson DW, Adams J, Wadsworth J, et al. Polycystic ovaries-a common finding in normal women. Lancet $1988 ; \mathrm{i}: 870-2$.

17 Beersiek F, Parks AG, Swash M. Pathogenesis of ano-rectal incontinence: a histometric study of the anal sphincter musculature. F Neurol Sci 1979;42: 111-27

18 Crowe R, Light JK, Chilton CP, Burnstock G. Vasoactive intestinal polypeptide (VIP)-immunoreactive nerve fibres associated with the striated muscle of the human external urethral sphincter. Lancet 1985;i:47-8.

(Accepted 20 September 1988)
Diabetes and Arthritis

Epidemiology Section and Epidemiology and Clinical Research Branch, National Institute of Diabetes and Digestive and Kidney

Diseases, National

Institutes of Health,

Phoenix, Arizona 85014,

United States

Mohammed F Saad, MD,

visiting associate

William C Knowler, MD,

chief of section

David J Pettitt, MD, assistant

chief of section

Robert G Nelson, MD, senior staff fellow

Peter H Bennett, MB, chief of

research branch

Correspondence to:

Dr Saad.

\title{
Transient impaired glucose tolerance in Pima Indians: Is it important?
}

\author{
Mohammed F Saad, William C Knowler, David J Pettitt, Robert G Nelson, Peter H Bennett
}

\section{Abstract}

As part of a continuing epidemiological study of noninsulin dependent diabetes among Pima Indians 154 subjects who had had a transient impairment of glucose tolerance were followed up for 1.2-16.9 (median 5.8) years after their glucose tolerance had returned to normal. Of these, 49 subsequently developed diabetes; 26 subsequently developed impaired glucose tolerance; and 79 had normal glucose tolerance at the last examination. The cumulative incidence of diabetes was $16 \%$ and $48 \%$ at five and $\mathbf{1 0}$ years of follow up respectively, compared with $3 \%$ and $8 \%$ for a control group of 1245 members of the same population. After adjustment for age, sex, body mass index, and plasma glucose concentration two hours after glucose loading the incidence of diabetes among the subjects who had had transient impaired glucose tolerance was $\mathbf{3 . 0}$ times that among the controls $(95 \%$ confidence interval $2 \cdot 1$ to $4 \cdot 3$ ). Proportional hazards function analysis indicated that obesity was the most important predictor of subsequent development of diabetes.

The results suggest that transient impairment of glucose tolerance indicates, at least in some subjects, a predisposition to diabetes and should not be considered clinically unimportant.

\section{Introduction}

The category impaired glucose tolerance was introduced in $1979^{1}$ and subsequently adopted by the World Health Organisation ${ }^{2}$ to include people who have glucose tolerance outside the normal range but not diagnostic of diabetes. Impaired glucose tolerance, however, is an unstable state. ${ }^{4}$ Riccardi et al reported that $34 \%$ of people with impaired glucose tolerance had normal glucose tolerance when tested again within two to four months. ${ }^{5}$ In several long term studies $24-53 \%$ of people who initially had impaired glucose tolerance had normal glucose tolerance within 10 years of follow up. ${ }^{6-9}$ Little is known, however, about the long term outcome in people with only a transient impairment of glucose tolerance. We report the outcome in 154 Pima Indians who had transient impaired glucose tolerance and were followed up for $1 \cdot 2-16 \cdot 9$ years after their glucose tolerance became normal.

\section{Subjects and methods}

We collected the data as part of a continuing epidemiological study of non-insulin dependent diabetes among Pima Indians who live in the Gila River Indian community in central Arizona. Subjects are examined biennially from the age of 5 . Each examination includes a medical history, a physical examination, and a modified oral glucose tolerance test in which a carbohydrate load equivalent to $75 \mathrm{~g}$ glucose is ingested after an overnight fast. In the early part of the study only plasma glucose concentration two hours after glucose loading was measured. Since 1975 fasting plasma glucose concentration has also been measured.

We studied 154 subjects with transient impaired glucose tolerance - that is, they had a plasma glucose concentration two hours after glucose loading of $7 \cdot 8$ $11 \cdot 1 \mathrm{mmol} / \mathrm{l}$; had had normal glucose tolerance (plasma glucose concentration at two hours $<7.8 \mathrm{mmol} / \mathrm{l}$ ) in al of the preceding examinations (median of two exami- 
nations, range one to seven), the most recent of which was 0.9-3.9 (median 2.2) years earlier; and had normal glucose tolerance in the subsequent examination within 1.3-3.9 (median $2 \cdot 2$ ) years. They were followed up for $1 \cdot 2-16 \cdot 9$ (median 5.8) years after their glucose tolerance had returned to normal to determine the prognosis of this transient impairment of glucose tolerance.

The subjects were divided into three groups according to changes in their glucose tolerance during the follow up: those who developed diabetes (fasting plasma glucose concentration $\geqslant 7.8 \mathrm{mmol} / 1$ or plasma glucose concentration two hours after glucose loading $\geqslant 11 \cdot 1 \mathrm{mmol} / \mathrm{l}$; those who had impaired glucose tolerance at the last examination; and those who had normal glucose tolerance at the last examination. The end point of the study for the first group of subjects was the date of diagnosis of diabetes, whether this was made at a biennial examination or as a result of a routine clinical examination, and the end point for the other subjects was the date of the last biennial examination.

The cumulative incidence of diabetes was estimated for the subjects being studied and for 1245 members of the same population (examined over the same period of time) who had normal glucose tolerance at the first three biennial examinations. The control subjects were followed up for 1.4-19.5 (median 8.3) years after the third examination.

The effects of several factors on the development of diabetes were determined when impaired glucose tolerance was present and at the subsequent examination when glucose tolerance was first recognised to have returned to normal. These factors were age, sex body mass index, triceps skinfold thickness, blood pressure, fasting plasma glucose concentration, plasma glucose concentration two hours after glucose loading, and serum cholesterol concentration. Body mass index (weight $(\mathrm{kg}) /$ height $(\mathrm{m})^{2}$ ) was used as a measure of obesity. People with a body mass index $\geqslant 27 \mathrm{~kg} / \mathrm{m}^{2}$ were considered obese..$^{10}$ Plasma glucose concentration was measured by the modified method of Hoffman. ${ }^{1}$ Serum cholesterol concentration was measured by the method described by Block et al. ${ }^{12}$

The logarithms of glucose concentrations were used in the statistical analysis to normalise the distributions. Statistical analyses were performed by programs of the SAS Institute. ${ }^{13}$ Comparisons among the three groups of subjects who had transient impaired glucose toler ance were performed by analysis of variance or the $\chi$ method. Mean values of continuous variables for each group were adjusted to the mean age of all subjects by linear regression.

The cumulative incidence of diabetes was estimated by the life table method (the Lifetest program).${ }^{13}$ The effect of different risk factors on decompensation to diabetes was evaluated by Cox's proportional hazards

Characteristics of subjects who had had transient impairment of glucose tolerance at time of subsequent normal glucose tolerance ${ }^{\star}$

\begin{tabular}{|c|c|c|c|c|}
\hline & $\begin{array}{c}\text { Subjects who } \\
\text { subsequently } \\
\text { developed diabetes } \\
(\mathrm{n}=49)\end{array}$ & $\begin{array}{l}\text { Subjects who } \\
\text { subsequently } \\
\text { developed impaired } \\
\text { glucose tolerance } \\
(\mathrm{n}=26)\end{array}$ & $\begin{array}{l}\text { Subjects who } \\
\text { continued to have } \\
\text { normal glucose } \\
\text { tolerance }(n=79)\end{array}$ & $\mathrm{p}$ Value \\
\hline Age (years) & 34 & 46 & 32 & 0.003 \\
\hline No of women & 34 & 16 & 51 & NS \\
\hline Body mass index $\left(\mathrm{kg} / \mathrm{m}^{2}\right)$ & $34 \cdot 8$ & $30 \cdot 7$ & $30 \cdot 3$ & 0.006 \\
\hline No obeset & 42 & 17 & 46 & $0 \cdot 005$ \\
\hline Triceps skinfold thickness (mm) & $30 \cdot 4$ & $25 \cdot 8$ & $23 \cdot 5$ & NS \\
\hline Systolic blood pressure (mm Hg) & 130 & 127 & 123 & NS \\
\hline Diastolic blood pressure $(\mathrm{mm} \mathrm{Hg})$ & 75 & 78 & 70 & NS \\
\hline Fasting plasma glucose $(\mathrm{mmol} / \mathrm{l})$ & $5 \cdot 3(n=11)$ & $5 \cdot 5(n=13)$ & $5 \cdot 3(n=41)$ & NS \\
\hline $\begin{array}{l}\text { Plasma glucose two hours after glucose } \\
\text { loading } \neq(\mathrm{mmo} / / \mathrm{l})\end{array}$ & & & & \\
\hline loading $\ddagger(\mathrm{mmol} / \mathrm{l})$ & $6 \cdot 2$ & $6 \cdot 3$ & $5 \cdot 8$ & NS \\
\hline Serum cholesterol $(\mathrm{mmol} / \mathrm{l})$ & $4 \cdot 4$ & $4 \cdot 5$ & $4 \cdot 3$ & NS \\
\hline
\end{tabular}

*Continuous variables were adjusted for age.

†Body mass index $\geqslant 27 \mathrm{~kg} / \mathrm{m}^{2}$

$\ddagger$ Means and $p$ values were computed after logarithmic transformation (base e).

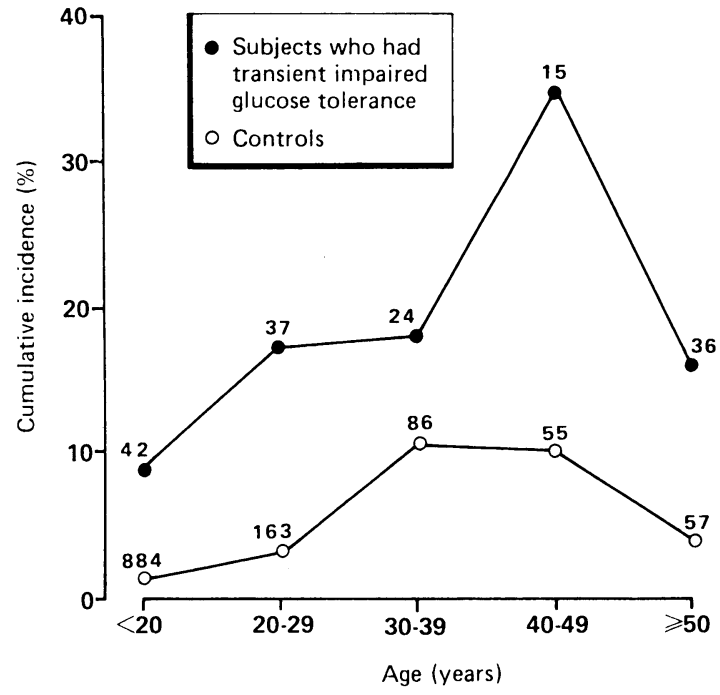

FIG 1 -Cumulative incidence of non-insulin dependent diabetes at five years in subjects who had had transient impairment of glucose tolerance and controls (at third examination) according to age at beginning of follow up. Numbers indicate numbers of subjects in each age group

function analysis (the PHGLM program). ${ }^{1+15}$ This analysis takes varying periods of follow up into account. Variables were first tested individually and subsequently analysed with the backward stepwise procedure to define those most predictive of progression to diabetes. Several models composed of different combinations of variables were studied. A quadratic function for age was included because of the non-linear relation between age and the incidence of diabetes in this population. ${ }^{16}$ All variables included in the different models satisfied the proportional hazards assumption.

\section{Results}

Of the 154 subjects studied, 49 subsequently developed diabetes 1.2-14.6 (median 5.5) years after their glucose tolerance returned to normal; 26 had impaired glucose tolerance at their last examination with a median follow up of $7 \cdot 0$ (range $2 \cdot 0-15 \cdot 0$ ) years; and 79 had normal glucose tolerance at their last examination with a median follow up of $5 \cdot 5$ (range $1 \cdot 6$ 16.9) years. The table shows the characteristics of the three groups of subjects at the beginning of follow upthat is, after their glucose tolerance had returned to normal.

The cumulative incidence of diabetes was $16 \%$ and $48 \%$ at five and 10 years of follow up respectively for the 154 subjects with transient impaired glucose tolerance and $3 \%$ and $8 \%$ respectively for the 1245 controls. The controls were on average younger (mean (SEM) age $20.0(0.4) v 35.0(1.5))$ and less obese (mean body mass index $\left.26.0(0.4) \mathrm{kg} / \mathrm{m}^{2} v 32.0(0.6) \mathrm{kg} / \mathrm{m}^{2}\right)$. Figure 1 shows the age specific cumulative incidence of diabetes at five years in the subjects with transient impaired glucose tolerance and controls. After adjustment for age, sex, body mass index, and plasma glucose concentration two hours after glucose loading the incidence of diabetes among the subjects with transient impaired glucose tolerance was 3.0 times that among the controls ( $95 \%$ confidence interval $2 \cdot 1$ to $4 \cdot 3)$.

Proportional hazards function analysis of pertinent variables, determined at the time glucose tolerance was impaired and after normal glucose tolerance had returned, indicated that obesity was the most important predictor of subsequent development of diabetes. The higher the body mass index or the triceps skinfold thickness the higher the incidence of diabetes. Backward stepwise multivariate analysis showed that only body mass index had a significant predictive value 
when the other variables were taken into account. The incidence of diabetes among obese subjects (body mass index $\geqslant 27 \mathrm{~kg} / \mathrm{m}^{2}$ after normal glucose tolerance returned) was 3.6 times that among non-obese subjects ( $95 \%$ confidence interval $1 \cdot 6$ to $8 \cdot 2$ ).

Figure 2 shows the changes in body mass index during the study in subjects who developed diabetes compared with those who continued to have normal glucose tolerance and those who reverted to having impaired glucose tolerance. Throughout the study the first group of subjects was significantly more obese than the two other groups $(\mathrm{p}<0.01$ by analysis of variance at each time point). All three groups, however, showed a progressive increase in mean body mass index during follow up.

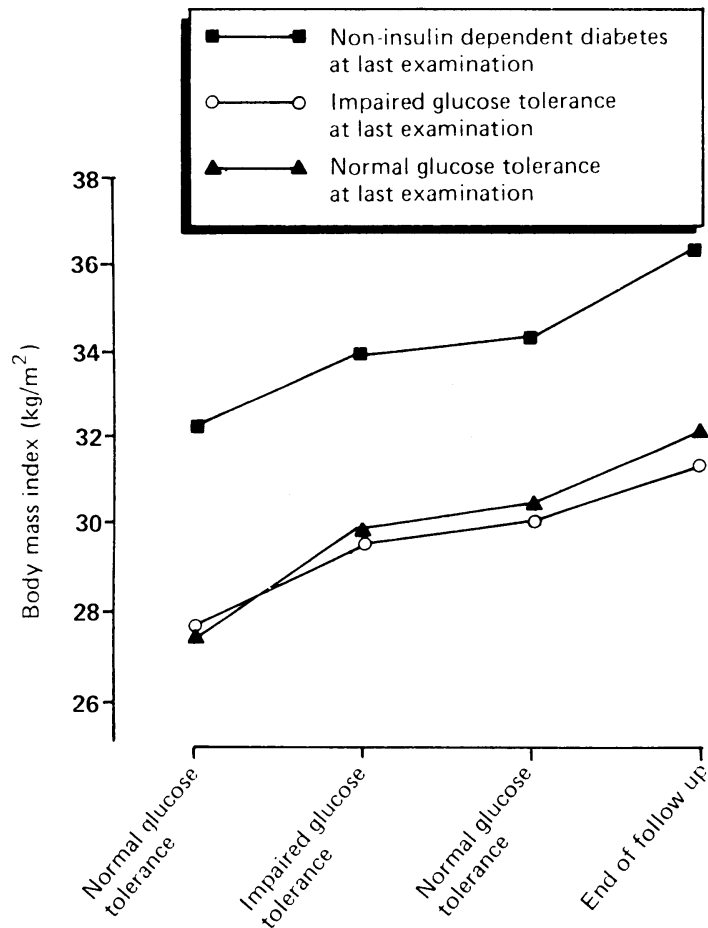

FIG 2-Sequential changes in mean body mass index in subjects with transient impairment of glucose tolerance during period of study shown according to their state at last examination

\section{Discussion}

Although their glucose tolerance reverted to normal, subjects who had had transient impaired glucose tolerance were at a higher risk of developing diabetes than those who had not had this abnormality. The cumulative incidence of diabetes at 10 years in the subjects with impaired glucose tolerance was $48 \%$. We emphasise that this study was carried out in a population with the world's highest incidence of non-insulin dependent diabetes. ${ }^{16}$ Nevertheless, the data indicate that a transient impairment of glucose tolerance is a marker for increased susceptibility to diabetes and should not be dismissed as clinically unimportant.

The cause of the transient impairment of glucose tolerance is not clear. Factors known to impair glucose tolerance such as diabetogenic drugs, changes in body weight or diet, and emotional or physical stress could not be incriminated in most of the subjects in this study. ${ }^{17}$ Only $13(8 \%)$ were taking drugs known to impair glucose tolerance (thiazides and oral contraceptives) when impaired glucose tolerance was present. At the time when impaired glucose tolerance was first recognised the body mass index of subjects was $8 \cdot 4$ (SEM $1 \cdot 0) \%$ higher than it had been at the previous examination, when glucose tolerance was normal. Reversion to normal glucose tolerance, however, was not associated with weight loss. On the contrary, a small increase in the average body mass index was observed $(2.8(0.8) \%)$ (figure 2$)$. Transient impairment of glucose tolerance in some subjects may be attributable to intrapersonal variation in glucose tolerance, ${ }^{1819}$ which is thought to be caused by fluctuation in the absorption, distribution, and utilisation of glucose, ${ }^{20}$ but this does not explain the high incidence of diabetes observed in subjects with this abnormality. We therefore postulate that a transient impairment of glucose tolerance indicates, at least in some subjects, a predisposition (possibly genetic) to non-insulin dependent diabetes that is manifested by occasional impairment of handling of a glucose load.

Obesity, as measured by body mass index or triceps skinfold thickness, was the most important risk factor for the development of diabetes among subjects who had had transient impaired glucose tolerance. Obese subjects had 3.6 times the incidence of the disease in non-obese subjects. Obesity plays a part in the development of non-insulin dependent diabetes ${ }^{21-23}$ and is associated with the development of hyperinsulinaemia and increased resistance to insulin. The mechanisms of increased resistance to insulin in obesity are thought to entail both receptor and postreceptor defects. ${ }^{24}$ In addition, morphological changes in muscle, particularly the enlargement of muscle cells and the consequent reduction in capillary supply to muscles, may contribute to the insulin resistance associated with obesity. ${ }^{26}$ In genetically predisposed subjects the increased demand for insulin eventually leads to the development of non-insulin dependent diabetes.

We conclude that subjects who have transient impaired glucose tolerance are at higher risk of developing non-insulin dependent diabetes than the general population. Transient impairment of glucose tolerance should not be dismissed as clinically unimportant. Subjects with this abnormality may benefit from interventions, such as advice on diet and increased physical activity, which might delay or prevent the development of diabetes.

We thank members of the Gila River Indian community for their cooperation; the laboratory and data processing staff of the research branch for their technical help; and Charlene $\mathrm{K}$ Gishie for typing the manuscript.

1 National Diabetes Data Group. Classification and diagnosis of diabetes mellitus and other categories of glucose tolerance. Diabetes 1979;28: 1039-57.

2 World Health Organisation expert committee on diabetes mellitus. Second report. WHO Tech Rep Ser 1980; No 646:9-14.

3 World Health Organisation. Diabetes mellitus. WHO Tech Rep Ser 1985; No 727:9-17.

4 Jarrett RJ Do we need IGT? Diabetic Med 1987:4:544-5.

5 Riccardi G, Vaccaro O, Rivellese A, Pignalosa S, Tutino L, Mancini M Reproducibility of the new diagnostic criteria for impaired glucose toler ance. Am 7 Epidemiol 1985;121:422-9.

6 Diabetes Survey Working Party. Ten-year follow-up report on Birmingham Diabetes Survey of 1961. Br Med $\mathcal{F} 1976$;ii:35-7.

7 Sartor G, Scherstén B, Carlström S, Melander A, Nordén Ả, Persson G. Tenyear follow-up of subjects with impaired glucose tolerance: prevention of diabetes by tolbutamide and diet regulation. Diabetes 1980;29:41-9.

8 Keen H, Jarrett RJ, McCartney P. The ten-year follow-up of the Bedford survey (1962-1972): glucose tolerance and diabetes. Diabetologia 1982;22: $73-8$.

9 Anger E, Thorsteinsson B, Eriksen M. Impaired glucose tolerance and diabetes mellitus in elderly subjects. Diabetes Care 1982;5:600-4

10 Burton BT, Foster WR, Hirsch J, Van Itallie TB. Health implications of obesity: an NIH consensus development conference. Int F Obes 1985;9: $155-70$

11 Anonymous. Technicon Autoanalyzer. Method file N-20. Tarrytown, New York: Technicon Instruments Corporation, 1965.

12 Anonymous. Technicon Autoanalyzer. Method file N-24a. Tarrytown, New York: Technicon Instruments Corporation, 1965.

13 SAS Institute. SAS user's guide: statistics. Version 5 . Cary, North Carolina: SAS Institute, 1985

14 Cox DR. Regression models and life tables. Fournal of the Royal Statistical Society. Series B. 1972;34:187-220.

15 SAS Institute. SUGI supplemental library user's guide. Version 5. Cary, North Carolina: SAS Institute, 1986

16 Knowler WC, Bennett PH, Hamman RF, Miller M. Diabetes incidence and prevalence in Pima Indians: a 19-fold greater incidence than in Rochester, Minnesota. Am f Epidemiol 1978;108:497-504. 
17 Shafrir E, Berman M, Felig P. The endocrine pancreas: diabetes mellitus. In: Felig P, Baxter JD, Broadus AE, Frohman LA, eds. Endocrinology and metabolism. 2nd ed. New York: McGraw-Hill, 1987:1108-9.

18 Ganda OP, Day JL, Soeldner JS, Connon JJ, Gleason RE. Reproducibility and comparative analysis of repeated intravenous and oral glucose tolerance comparative analysis of repe
tests. Diabetes 1978;27:715-25.

19 Olefsky JM, Reaven GM. Insulin and glucose response to identical oral glucose tolerance tests performed forty-eight hours apart. Diabetes 1971;23:449-53.

20 Harding PE, Oakley NW, Wynn V. Reproducibility of oral glucose tolerance data in normal and mildly diabetic subjects. Clin Endocrinol (Oxf) 1973;2: $387-95$.

21 Knowler WC, Pettitt DJ, Savage PJ, Bennett PH. Diabetes incidence in Pim Indians: contributions of obesity and parental diabetes. Am $\mathcal{J}$ Epidemio $1981 ; 113: 144-56$

22 Wilson PW, McGee DL, Kannel WB. Obesity, very low density lipoproteins and glucose intolerance over fourteen years: the Framingham study. $A m \mathcal{F}$ Epidemiol 1981;114:697-704.
23 Modan M, Karasik A, Halkin H, et al. Effect of past and concurrent body mass index on prevalence of glucose intolerance and type 2 (non-insulindependent) diabetes and on insulin response: the Israel study of glucose intolerance, obesity and hypertension. Diabetologia 1986;29:82-9.

24 Kashiwagi A, Bogardus C, Lillioja S, et al. In vitro insensitivity of glucose transport and antilipolysis to insulin due to receptor and post receptor a abnormalities in obese 7

25 Amatruda JM, Livingston JN, Lockwood DH. Cellular mechanisms in selected states of insulin resistance: human obesity, glucocorticoid excess, and chronic renal failure. Diabetes Metab Rev 1985;1:293-317.

26 Lillioja S, Young AA, Cutler CL, et al. Skeletal muscle capillary density and fiber type are possible determinants of in vivo insulin resistance in man. J Clin Invest 1987;80:415-24.

(Accepted 7 September 1988)

\title{
Physical activity and calcium intake in fracture of the proximal femur in Hong Kong
}

\author{
E Lau, S Donnan, D J P Barker, C Cooper
}

\begin{abstract}
In Hong Kong physical activity and calcium intake of 400 Chinese men and women with hip fractures were compared with those of $\mathbf{8 0 0}$ controls. Daily walking outdoors, upstairs, uphill, or with a load protected against fracture. This was independent of cigarette smoking and alcohol consumption. Higher levels of reported activity in middle life were also protective. Average calcium intake was around one quarter that in Britain because of the low consumption of dairy products. Differences in calcium intake depended mainly on consumption of green vegetables and small fish. High intake protected against hip fracture.

These findings point to the importance of maintaining daily physical activity and calcium intake in urbanised Chinese populations.
\end{abstract}

\section{Introduction}

Hip fractures are an increasing public health problem among elderly Chinese in Hong Kong. ${ }^{12}$ This population eats a traditional Chinese diet, which is low in calcium, and urbanisation has reduced their physical activity. The contribution of these two factors to the rising incidence of fracture is unknown. We compared calcium intake and activity in elderly Chinese men and women with hip fractures and controls of similar ages.

\section{Patients and methods}

The study group comprised 400 patients with radiologically diagnosed hip fracture who were admitted consecutively to the orthopaedic wards of two main hospitals in Kowloon. Their activity and diet were compared with those of two sets of controls. Hospital controls comprised surgical inpatients from the wards of the same hospital. No diagnostic groups were excluded, and the first patient admitted after the case of the same sex and within five years of age was recruited. Community controls came from two sources. For patients aged over 70 they were systematically sampled from a register for the old age allowance in Shatin; for patients aged under 70 controls were randomly selected from attenders at the Chinese University general practice unit in Shatin. Community controls were individually matched to the patients by sex and five year age group. When a control refused to participate a substitute was selected.

All patients in the study group and controls were interviewed by one of two trained interviewers with a structured questionnaire. They were asked about their history of falling, cigarette smoking, and alcohol consumption. The usual frequency of carrying out various forms of weight bearing physical activity was assessed by inquiring about the frequency of walking outdoors, upstairs, uphill, and with a load during the six weeks before admission to hospital. The frequencies of walking uphill and with a load at around the age of 35 were used as indices of past physical activity. Current calcium intake was assessed from the weekly frequency of consumption of nine foods that contain calcium and are commonly eaten in the Chinese diet. The intake was calculated from the calcium content of each food, typical portion sizes, and the frequency of consumption in a week. The results tended to underestimate the total intake.

The data were analysed with a conditional multiple logistic regression for matched case-control studies. As the estimates of relative risk when patients in the study group were compared with community controls were similar to those obtained when they were compared with hospital controls the two control groups were amalgamated.

\section{Results}

Eighteen patients could not be interviewed because of their poor mental state, and additional patients were recruited to make up 400 . The rate of response among the controls was $90 \%$. Table I shows the age and sex distribution of the patients in the study group. There were more older women, and the totals were 280 women and 120 men. Significant increases in the risk of hip fracture were found in people who were current or previous cigarette smokers (relative risk $=1 \cdot 3,95 \%$ confidence interval 1.0 to $1 \cdot 7$ ), who consumed alcohol daily $(3.9,2 \cdot 3$ to $6 \cdot 7)$, and who had reported a fall within the previous year $(1 \cdot 8,1 \cdot 3$ to $2 \cdot 5)$.

Table II shows the relation between current physical activity and the relative risk of hip fracture. Among women the risk was up to $2 \cdot 1$ times greater in those who reported walking outdoors, upstairs, uphill, or with a load less than once a day. After adjustment for cigarette smoking and alcohol consumption the TABLE I-Age and sex distribution of patients with hip fracture

\begin{tabular}{lcr}
\hline Age (years) & Women & Men \\
\hline$<70$ & 54 & 47 \\
$70-79$ & 108 & 45 \\
$\geqslant 80$ & 118 & 28 \\
\hline Total & 280 & 120 \\
\hline
\end{tabular}

Correspondence to: Dr Lau.

\author{
D J P Barker, FRCP, director \\ C Cooper, MRCP, \\ epidemiologist \\ Department of Community
Medicine, Chinese \\ University of Hong Kong, \\ Hong Kong \\ Epidemiolog Unit, \\ Southampton, \\ Southampton General \\ Hospital, Southampton
}

